\title{
Do INVESTORS RATIONALLY Evaluate Investment Fees? A Behavioral Finance Investigation
}

\author{
Edward Hutton, Kevin Ryan, and fohn Osberg
}

Edward Hutton is Assistant Professor of Finance, Niagara University. Kevin Ryan and John Osberg are undergraduate students majoring in finance at Niagara University.

This research was supported in part by a grant from the Niagara University Research Council Correspondence concerning this article should be addressed to Edward Hutton, Niagara University College of Business, 158 Bisgrove Hall, Niagara University, NY 14109; E-mail: ehutton@niagara.edu, Phone: 716-286-8209

\begin{abstract}
This study proposes a new behavioral finance bias, related to the evaluation of investment fees by investors following a significant period of declining investment returns. Financial theory suggests that investors would seek to minimize their total cost of investment fees but we show that where investors experience falling returns, some will chose the funds with higher fees, even though that choice leads to lower overall returns. A possible explanation may be the expectation that investors felt these higher fees were
\end{abstract}


indicative of better management and a better future return. The implications of these biases will be discussed as they relate to how investors evaluate investment fees, and how this understanding affects their portfolio selection. DOI: http://dx.doi.org/10.15239/ jacadb.2014.111

Keywords: behavioral finance, investment fees, and portfolio choice

DOI: http://dx.doi.org/10.15239/j.brcacadjb.2014.04.01.ja03

\section{INTRODUCTION}

As of 2010 , there is over $\$ 20$ trillion dollars invested in investment accounts. Of this amount, almost half is in professionally managed accounts, or accounts where an advisor/investor relationship exists. An investment advisor can provide a range of services to investors, including selection of investments, allocation of investment choices, determining investor suitability, and keeping and preparing records of investment performance. In return for managing an investment account, an advisor expects some form of compensation for the services they render. Many models for compensation exist, such as sharing of investment returns, hourly fees, annual retainers, and transaction commissions. One of the most common is the investment fee annual charge, wherein a percentage of the overall portfolio is paid to the investment advisor. For example, and advisor managing a $\$ 100,000$ portfolio with a $1 \%$ fee would receive $\$ 1,000$ per year as a fee. This fee is normally deducted from the balance in the portfolio, so that an investment that yields a $5 \%$ gross return would increase by only $4 \%$ after the deduction of a $1 \%$ fee.

Financial theory demonstrates that investors seek to maximize their investment return while reducing their risk, and that they would be expected to make investment decisions that maximize return per unit of risk. Since an investment fee reduces overall return, a rational investor 
would expect to pay fees only to the extent that their return is greater, or their risk lower, than it would be in the absence of the fees paid to the investment advisor. To make this decision, an investor should evaluate the ability, experience, and all other relevant data regarding an investor advisor.

The relatively new discipline of behavioral finance investigates the effect that psychological biases have on monetary decision making, including the findings that investors suffer from innate behavioral biases which make them irrational in their decision framing and making processes regarding investment choices. These relevant behavioral biases include overconfidence, self-attribution, illusion of control, disposition effect, cognitive dissonance, and herding (Nofsinger, 2002). These biases lead to a lowering of overall investor welfare (Stoughton, 2011; Johnson, 2009; Freeman, 2006). Many experiments exhibit this lowering of investor welfare, in addition to an increasing amount of data available relating to advisor fees and returns (Balyeate, 2007; Stoughton, 2011).

In this paper, we examine whether there exists an additional behavioral bias that influences the ability of an investor to rationally evaluate the tradeoffs between investment fees and investor welfare. In other words, can investors be expected to make the correct choice among investment funds with different fee structures in terms of the expected increased investment returns or lower risks?

If this bias exists, it would be expected to have significant effects on overall investor welfare. In particular, this irrationality may cause crucial flaws in the retirement planning system. With the diminishment of institutionally managed defined benefit plans, such as pensions, and the subsequent increase in individually managed defined contribution plans, such as the $401(\mathrm{k})$ plan, the lack of public knowledge and false perceptions regarding investment fees may have a significant effect on the retirement system. 
The paper adds to the topic of behavioral finance literature by relating it to investment fees and the way in which investors evaluate them. These fees are highly relevant to investors, especially given the very long expected investment horizon (30-50 years) often found in retirement accounts. The misinterpretation of fees can lead to a lowering of investor welfare and an amplification of investment losses and the effects of psychological biases

\section{LITERATURE REVIEW}

The bias of overconfidence states that investors tend to overestimate their knowledge and ability to control events. Nofsinger (2002) relates overconfidence to investing by relating how investors believe that they can select investments that will outperform the overall market even on a risk-adjusted basis. Nofsinger also explains how the disposition effect causes investors to sell winners early, seeking the feeling of pride for picking a winner, and hang on to losers for too long, fearing the regret associated with having picked a loser. Contributing to the behavioral bias literature, Brav and Heaton (2002) argue, "the limits of arbitrage will be especially severe if cognitive biases are themselves related to structural uncertainty." They also explain the overreaction/under reaction theory, whereby investors reaction towards new information is not scaled to the importance of that information to the possible effects on their portfolios.

Allen and Evans (2005) establish the relevance of investment experience for demonstrating the overconfidence effect, showing that as many as $40 \%$ of bidders in an experiment were overconfident in their model; and that this number increased with increased prior experience.

Nguyen and Schubler (2012) explain that while experience tends to decrease the negative effects of certain biases by causing investors to adopt less risky strategies, they also support Nofsinger by stating that sophisticated investors tend to attribute successes to their own abilities and failures to external factors, which they refer to as the illu- 
sion of control. Chen, Kim, and Nofsinger (2007) document that these behavioral biases are seen significantly in middle-aged investors, the primary market for retirement funds. They relate demographic effects further by showing that sophisticated investors are more likely to follow momentum trading strategies.

Das (2009) adds to this discussion, explaining how fee structure influences portfolio selection incentives of the advisor, affects risk shared between the investor and advisor, and acts as (sometimes false) statement of quality by superior investment advisors. Das and Sundaran (2002), explain that higher fees are more often an incentive for advisors to take more risk in their investments because they believe they are protected from much of the downside. They also claim that higher fee structures may act as signals of advisors abilities.

According to Johnson (2009), few investors knew they even paid advisory fees as a percentage of returns, and even fewer had an idea what that percentage actually was. His conclusion is that disclosure and education are the best avenues to making better fee evaluations. Brown and Freeman (2006) relate that fund advisors may be overcompensated based on poorly disclosed and complex fee structures. They relate that in funds with below average fees investors are much better off. They also discuss that the issues from these fees exist in part due to a shortage of quality information disclosed by the advisors and funds exists specifically to prevent investors from deciphering an unfair fee and pricing structure for their investments.

The industry shouldn't abandon the current model though, as Stoughton, Wu, and Zechner (2011) argue that the coupling of rational investors with a competitive advisory industry will always lead to increased investor welfare. Goetzmann and Massa (2003) add to this by concluding that the effects seem to extend beyond lowered investor welfare and returns, reaching company returns as well. 
Balyeate (2007) finds that when investors are subject to behavioral biases, or the negative effects of competition induced arbitrage, that education and disclosure might be the solution. Coates and Hubbard (2007) discuss some of the prior government intervention, by reporting that Congress, in the ICA Section 36(b) ruling, established an upper bound on the range of fees that an advisor could charge to a fund. According to West (2012), irrational decisions are experienced by both sophisticated and unsophisticated investors because investors experience behavioral biases and either cannot obtain or understand the product and service descriptions.

West (2012) concludes that "the aims and objectives of the FLE [Financial Literacy Education] programs should be to not only educate consumers about financial markets and products but to highlight to individuals the personal biases and limitations that they, as humans, cannot easily avoid".

Finally, as retirement planning effects are concerned, Cendrowski (2012) is a major contributor to the literature regarding the effects of these fees. According to Cendrowski (2012) the ordinary American household will lose approximately $\$ 155,000$ in $401(\mathrm{k})$ fees over the lifetime of two working adults as a result of either not understanding investment fees or because they did not know these fees existed at all

\section{Experimental Design}

University students were recruited to participate in a computer investment simulation. Participants were paid a small honorarium (\$10.00) for completing the simulation, and incentivized to achieve the best possible investment results through an additional payment (\$10.00) offered to those who achieved the highest overall investment returns.

At the beginning of the experiment, each participant completed a demographic and risk tolerance survey. A copy of this survey is given in 
Appendix A. There were two sessions run, involving 23 and 20 participants. A standardized script was read to all participants, explaining the simulation program, and the incentive payment for those achieving the highest investment returns. In the simulation, each participant was given an initial $\$ 100,000$ endowment, and told to select one of 4 different stock investment funds, generically labeled Funds A, B, C, and D, or a money market account. They made their choices by selecting the percentages they wished to allocate to each of these five investment choices, for example, 25\% in Fund A, 20\% in Fund B, 55\% in Fund C, and 0\% in Fund $\mathrm{D}$ or the money market account.

In the instructions given to participants, only a limited amount of information about each investment fund was given. They were told that while each stock fund had the same average 10 year return of $8 \%$, the results could be highly variable and could range from a gain of $40 \%$ to a loss of $40 \%$ in a period. They were told that each fund charged a different investment fee each period, and that the fee would be deducted from their investment results. The fees for Fund A were set at .2\% (20 basis points), for Fund B at .5\% (50 basis points), Fund C at 1.5\% (150 basis points) and for Fund D at $2.0 \%$ (200 basis points). Finally, the money market fund was presented as having a constant $2 \%$ return per period, with no investment fee.

The instructions gave no other information about the strategy followed by each fund. This limited information meant that participants made initial choices between funds knowing only the past 10 year average return (the same for all stock funds), the investment fees (ranging from 20 to 200 basis points for the stock funds, and zero for the money market funds) and the level of volatility (high for the stock funds, and low for the money market fund). In subsequent periods, participants also had knowledge of how their chosen funds had performed in the past periods as well.

The experiment was conducted across a network configuration, utilizing a custom Visual Basic Application (VBA) program. A central 
network control program controlled the performance of each fund in each round. A screen shot of the participant screen is given in the appendix.

After all participants made their choices, the round was closed. The participant's choices were communicated to the central server, which contained a pre-programmed set of investment returns for each fund for every round. Using the participant's allocations choices, their endowment amounts, and the investment results, the central program calculated the gross investment returns and then deducted the appropriate investment fee. The return of each fund, the fee deduction, and the overall investment return of the participant in that round were then displayed to the participant. After being given 2 minutes to evaluate their results, the participants were then given another 2 minute period to make another set of investment choices.

At the beginning of the experiment, a trial period was conducted. Every participant was asked to select equal amounts (20\%) of each of the five funds, and the results tabulated and revealed to the participants. Since the initial endowments were all equal, and the investment choices equal, each participant was expected to achieve the same result. After ensuring that all participants understood the experiment, the experiment was reset to the initial conditions.

In the experiment, investment choice was repeated over a total of 10 rounds, with the overall return of the portfolio shown as an aggregate number after each round, in addition to last round's return of each fund, the total monetary amount lost or gained in that fund, the total amount removed from the returns by the fees, and the total return for that round. After completing ten rounds, the experiment was stopped and the participants with the three highest overall investment returns were given the additional incentive payment.

With the use of the central server model, any combination of investment period returns could be utilized over the ten rounds. In this exper- 
iment, we developed a 10 period sequence of base returns that grew modestly in periods $1-4$ (returns ranged from $2-8 \%$ per period), declined significantly in period 5-8 (returns ranged from $-10 \%$ to $-41 \%$ ), and grew at a high rate in the final 2 periods (returns of $+20 \%$ and $+32 \%$ ). For the four stock Funds A, B, C and D, the returns on a particular fund in a period was calculated by taking the base return and adding a random factor that modified the base return. In this way, the difference in return on the stock funds came from the deterministic base rate and the random factors; there were no difference in the returns of the different funds due to their fee structures.

\section{Results AND Analysis}

This experiment will be analyzed using several regression models using the same dependent variable: average fees. "Avgfees" is the major focus for this study because it is a summarized indicator of the various fees chosen (on average by round) by each participant. For each participant in each round, we calculated a weighted average of the total investment fee paid, as follows:

$$
\begin{aligned}
& \text { Avgfees }=\left(\% \mathrm{~F}_{\mathrm{A}} * \mathrm{IF}_{\mathrm{A}}\right)+\left(\% \mathrm{~F}_{\mathrm{B}}{ }^{*} \mathrm{IF}_{\mathrm{B}}\right)+\left(\% \mathrm{~F}_{\mathrm{C}}{ }^{*} \mathrm{IF}_{\mathrm{C}}\right)+\left(\% \mathrm{~F}_{\mathrm{D}}{ }^{*} \mathrm{IF}_{\mathrm{D}}\right) \\
& +\left(\% \mathrm{~F}_{\mathrm{MM}}{ }^{*} \mathrm{IF}_{\mathrm{MM}}\right)
\end{aligned}
$$

Where $\% \mathrm{~F}_{\mathrm{X}}=$ participant allocation to Fund $\mathrm{X}$, and $\mathrm{IF}_{\mathrm{x}}=$ Investment Fee of Fund X

To prepare our results for analysis, we pooled together from both sets of experiments, for each time period. This gave us 43 observations of Avgfees for each time period.

A multivariate regression analysis was run to evaluate the relationship between the period returns and the average fees paid. To relate the hypothesis to a regression setup, we expected that the period returns should be inversely related to the average fees paid. The regression 
results shown in Table 1 confirm this hypothesis for almost all period returns.

The negative Beta coefficients for all period returns, except rounds 4 and 5, display that the inverse relationship was present between average fees and the period return. This can be further explained to state that if the period returns were lower, average fees were higher for that round. As the participant lost money, the average fees they paid actually increased. Rounds 4 and 5 were positively correlated but, after further observation, this may have been due to the positive returns players experienced during those rounds.

The p-values for rounds 2,5,6,7, and 9 indicated those independent variables were significant at the $95 \%$ confidence level, while the remaining variables were shown to be significant at the $90 \%$ confidence level. Rounds 9 and 4 were not significant at the $90 \%$ confidence level (although 4 could have been assumed to be due to its close proximity). Those variables remained in the model after passing the Partial F-Test, in which they were removed and the F-Test p-value increased. An important note must be made for variable r10t, which was the total return following the last round of the simulation.

The high $\mathrm{R}^{2}$ value and very low $\mathrm{p}$-value for the F-Test indicated that the model was significant, and that the independent variables had a high level of explanatory power over the dependent variable (average fees paid). The fact that the Adjusted $R^{2}$ value was close to the $R^{2}$ helped conclude that the variables remaining in the model were all necessary to the model. Table 5 indicated a lack of collinearity issues in the regression.

To determine the presence of heteroskedasticity, or non-constant variance, White's test was conducted. This test returned a fail to reject on the null hypothesis, explaining that the data was not heteroskedastic, and that non-constant variance was absent from the model.

To further analyze the experimental data, a cross sectional data analysis of demographic data vs. average fees was conducted. The regres- 
sion model was run originally with all variables in the summary statistics in Table 1. However, most variables were removed following partial FTest and T-Test evaluations whose results indicated that the model had better explanatory power over the variation in the dependent variable without those variables. Important demographic discussion points based on the summary statistics are shown in Table 1.

The regression model in Table 3 shows the regression results. Special attention should be paid to the coefficient, $p$-value, $R^{2}$, Adjusted $R^{2}$, and F-Test p-value. As far as the coefficients are concerned, while the effect of the independent variables' Betas on the dependent variable's variation is low for all variables, all are positively correlated. This means that as each of these variables increase, the averages fees paid also increase.

The p-values for the variables in Table 3 indicate that all variables which passed the partial F-Test (and therefore remained in the model) were significant at the $95 \%$ confidence level $(p<0.05)$. The only exception was GPA, which was significant at the $90 \%$ confidence level. The low $\mathrm{R}^{2}$ indicated that the variance in the independent variables did not explain a high level of the variance in the dependent variable. The independent variables did explain it to some degree, however; and the Adjusted $\mathrm{R}^{2}$ value within a reasonable range of the $R^{2}$ confirms that the remaining variables in the model were useful variables.

The F-Test $p$-value $<0.05$ indicated that the model's independent variables had explanatory power over the dependent variable. This is important to note for the purpose of categorizing investors and identifying what could potentially be causing certain biases to occur..

From this analysis, it appears that GPA, age, investment experience, and tendency to accept investment risk are all positively correlated to Average Investment Fees. There is an inverse relationship in the assume loss variable, which indicates a contradiction to the tendency to increasing investment risk being positively correlated to average investment fees 
An analysis of independent variables does not indicate collinearity being present. White's test was conducted to determine the presence of heteroskedasticity, and returned a fail to reject on the null hypothesis. This explains that the data was not heteroskedastic, and that nonconstant variance was absent from the model.

\section{Discussion}

There are several factors that limit the broad applications of the conclusions of our current study. Ideally, our experiment participants would have had a much wider range of age levels and investment experience. With a broader sample of participants, especially if those participants had several years of investing experience, we may have reached different conclusions. It should be noted, however, that new investors in defined contribution plans such as $401 \mathrm{k}$ plans or IRA's may also lack any substantial investment experience.

We also note that, in general, our participants had only a modest amount of knowledge of investment finance. Many of the negative effects of paying recurring investment fees may not have been fully realized by those in the study, so they may not have fully aware of the compounding effect of paying higher fees across several time periods.

Finally, due to time constraints, our experiment only contained ten "years" (investment periods) of realized returns. Its not unreasonable to believe that if the experiment had been conducted for many more periods, such as 20 or 30 , that participants would have learned through experience that the higher fee funds did not result in better overall performance, and the behavioral anomaly would have been reduced or eliminated. The results of the financial experiment conducted, which evaluated and discussed behavioral biases on investment allocation choices, seem to support that under limited conditions a behavioral bias exists, and that investors may not in fact rationally evaluate investment fees. In this case, individual investors (especially those relatively non- 
sophisticated investors in defined contributions plans) when faced with allocation choices based upon management fees and previous return data, will irrationally manage their money by choosing higher fund fees during periods of declining return. While the reasoning behind that decision has many factors, we are led to believe from our study that this is due to those investors concluding that those fees are indicative of higher future return and better management. By showing that an increase in experience, investment knowledge, and risk tolerance positively correlates to greater tendency toward choosing higher investment fees, it is possible to then conclude that behavioral biases were responsible for the irrational decisions.

The identified behavioral biases are related to overconfidence and selfattribution, which lead to individuals being overconfident in their ability to evaluate information. In this instance, this information includes the investment management fees present on each of the funds. In addition, the disposition effect, which caused investors to react emotionally to prior events, and cognitive dissonance, which causes investors to block out previous events which conflict with positive self-image, were also evident. These caused investors to make quick decisions based on recent losses and to ignore the fact that choosing higher investment fees may have led to a further decreased return in prior experiences.

Based on the experiment and our analysis, we believe that investors may choose to lower their own welfare by irrationally choosing higher fee investment choices. This topic is highly relevant to the sizeable retirement fund structure in the United States which is based heavily on the use of investment management fees. As a result of behavioral finance biases, investment fees can cause investors to make misinformed decisions harmful to their ability to manage a successful retirement portfolio. 


\section{REFERENCES}

Allen, W. D., \& Evans, D. A. (2005). Bidding and overconfidence in experimental financial markets. The fournal of Behavioral Finance, 6(3), 108-120. http://dx.doi.org/10.1207/s15427579jpfm0603_1

Bailey, W., Kumar, A., \& Ng, D. (2011). Behavioral biases of mutual fund investors. Journal of Financial Economics, 102(1), 1-27. http://dx.doi. org/10.1016/j.jfineco.2011.05.002

Balyeat, R. B. (2007). A class experiment: The dollar auction as a teaching tool to demonstrate the theories of behavioral finance. fournal of the Academy of Business Education, 8 (34-41).

Brav, A., \& Heaton, J. B. (2002). Competing theories of financial anomalies. Review of Financial Studies, 15(2), 575-606. http://dx.doi.org/10.1093 $/ \mathrm{rfs} / 15.2 .575$

Chen, G., Kim, K. A., Nofsinger, J.R., and Rui, O.M. (2007). Trading Performance, Disposition Effect, Overconfidence, Representativeness Bias, and Experience of Emerging Market Investors. Journal of Behavioral Decision Making, 20, 425-451. http://dx.doi.org/10.1002 /bdm.561

Coates IV, J. C., \& Hubbard, R. G. (2007). Competition in the mutual fund industry: Evidence and implications for policy. Journal of Corporate Law. 33, (151-165).

Das, S.R., and Sundaram, R.K. (2002). Fee Speech: Signaling, Risk Sharing, and the Impact of Fee Structures on Investor Welfare. The Review of Financial Studies, 15(5), 1465-14970. http://dx.doi.org/10.1093/rfs/ 15.5.1465

Freeman, J. P. (2006). Mutual fund advisory fees: The cost of conflicts of interest. Retrieved from http://dx.doi.org/10.2139/ssrn.923879

Goetzmann, W. N., \& Massa, M. (2003). Disposition matters: volume, volatility and price impact of a behavioral bias (No. w9499). National Bureau of Economic Research. http://dx.doi.org/10.2139/ssrn.923879

Luo, G. Y. (2012). The psychological explanation of asset price over reaction and under reaction to new information: representativeness 
heuristic and conservatism bias. Fournal of Accounting and Finance, 12(2), 38-50.

Nguyen, T., \& Schuessler, A. (2012). Investment decisions and sociodemographic characteristics-empirical evidence from Germany. International fournal of Economics and Finance, 4(9), 1. http://dx.doi. org/10.5539/ijef.v4n9p1

Nofsinger, J. R. (2002). The Psychology of Investing. Upper Saddle River, NJ: Prentice Hall.

Ritter, J. R. (2008). Forensic Finance. The fournal of Economic Perspectives, 22(3), 127-147. http://dx.doi.org/10.1257/jep.22.3.127

Stoughton, N.M., Youchang, W. \& Zechner, J. (2011). Intermediated investment management. The fournal of Finance, 156, 3.947-980. http:// dx.doi.org/ 10.1111/j.1540-6261.2011.01656.x

Sundali, J.A., \& Guerrero, F. (2009). Managing a 401(k) account: An experiment on asset allocation. The fournal of Behavioral Finance, 10, 108-124. http:// dx.doi.org /10.1080/15427560902902135

West, J. (2012). Financial literacy education and behavior unhinged: combating bias and poor product design. International Journal of Consumer Studies, 36(5), 523-530. http://dx.doi.org/10.1111/j.14706431.2012.01118.x

\section{Web Appendix}

The web appendix for this paper is available at:

http://dx.doi.org/10.15239/j.brcacadjb.2014.04.01.wa03

\section{Citation Information}

Hutton, Ed, Kevin Ryan, and John Osberg. "Do Investors Rationally Evaluate Investment Fees? A Behavioral Finance Investigation." The BRC Academy fournal of Business 4, no. 1 (2014): 39-53. http:// dx.doi.org/10.15239/j.brcacadjb.2014.04.01.ja03 